Удк 633.16:631.523.2

DOI 10.36461/NP.2020.54.1.009

\title{
НАСЛЕДОВАНИЕ И ГЕНЕТИЧЕСКИЙ КОНТРОЛЬ ВЫСОТЫ РАСТЕНИЙ У ЯЧМЕНЯ
}

\author{
Д. О. Долженко, канд. с.-х. наук
}

Пензенский институт сельского хозяйства - филиал федерального государственного бюджетного научного учреждения «Федеральный научный центр лубяных культур», Россия, Пензенская область, р. п. Лунино, т. +7 (84161) 3-18-07, e-mail: d. dolzhenko. pnz@fnclk.ru

Изучено наследование высоты растений у ячменя в системе диаллельных скрещиваний $(6 \times 6)$ в условиях лесостепи Среднего Поволжья в контрастные по гидротермическому режиму годы. Анализ комбинационной способности по B. Griffing и генетический анализ по B. Hayman показали преобладание аддитивных эффректов в контроле признака (наследование по типу полного и неполного доминирования). Признак должен быть отзывчив на отбор, что подтверждают и коэффициенты наследуемости: в широком смысле $\left(\mathrm{H}^{2}\right)$ 0,85-0,90; в узком смысле $\left(h^{2}\right)-0,52-0,62$. Высоту растений увеличивали доминантные гены. Наличие комплементарного эпистаза увеличивает вероятность получения отрицательных трансгрессий, повышая успех селекции на снижение высоты растений. Ни один из сортов диаллельного комплекса не обладал всеми рецессивными аллелями, уменьшающими признак. Сорта Анна и Омский голозёрный 1, обладающие доминантными аллелями, будут увеличивать высоту растений в потомстве. Данные сорта следует использовать в комбинациях с более низкорослыми родителями. Сорта Condor и Margret имеют более высокое число рецессивных аллелей и могут рассматриваться как доноры снижения высоты. Выделены перспективные для селекции гибридные популяции.

Ключевые слова: ячмень, диаллельный анализ, высота растений, генетические системы, комбинационная способность, коэффициент наследуемости.

\section{Введение}

Высота растений - важный признак для ячменя в Среднем Поволжье. Высокие растения часто склонны к полеганию, что особенно характерно для сортов степного агроэкотипа. В европейских странах проблема полегания решается созданием короткостебельных сортов [1, 2]. Например, в Германии высота ячменя снижена до $60 \mathrm{~cm}$ [3]. Однако в Поволжье ячмень должен иметь высоту не менее 70 см, чтобы при раздельной уборке не проваливался валок [4] и не затруднялась уборка в острозасушливые годы $[5,6]$. Поэтому при селекции сортов ячменя для лесостепи Среднего Поволжья важно соблюсти оптимальные параметры высоты растений - не ниже 60 см в засушливый год.

Знание закономерностей наследования признака облегчает задачу селекционера. По литературным данным высота растений может контролироваться различными генетическими системами.

В исследованиях В. А. Горшковой, выполненных в условиях ЦентральноЧернозёмной зоны, высота растений ячменя наследовалась по типу неполного доминирования, доминантные аллели увеличивали признак, рецессивные - снижали [7]. Неполное доминирование обнаружено и в опытах A. K. Verma с соавторами [8], причём были доказаны также эпистатические эффректы, проявление которых зависело от места исследований. Преимущественно доминантными эфффектами генов контролировалось наследование высоты в скрещиваниях двурядных озимых форм в исследованиях сербских учёных [9].

В Институте генетики растений (Польша) на дигаплоидных линиях ячменя была показана существенная роль аддитивных эффектов в контроле высоты растений [10]. В других экспериментах признак контролировался, в основном, аддитивными и доминантными эффректами генов, проявлялся также эпистаз типа «аддитивный $\times$ аддитивный» [11] и «доминантный $\times$ доминантный» [12]. Аддитивным действием генов объяснялось и наследование высоты в исследованиях в Азербайджане [13], США [14].

В опытах Института сельского хозяйства и технологии (Индия) высота растений наследовалась по типу сверхдоминирования с участием аддитивных эфффектов; доказана также существенность неаллельных взаимодействий (дупликатный и комплементарный эпистаз) [15].

В исследованиях Л. И. Королевой (Московская обл.), в поколении $F_{1}$ преобладало 
сверхдоминирование. Увеличение признака связано с доминантными, снижение - с рецессивными генами [16].

В большинстве случаев на проявление генетического контроля высоты растений влияли условия среды. Поэтому целью исследований, проведённых в 2008-2010 гг. в Пензенском НИИСХ, было изучение генетического контроля высоты растений в конкретных почвенно-климатических условиях - на выщелоченном чернозёме лесостепи Среднего Поволжья.

\section{Методы и материалы}

Объектом исследования служил полный диаллельный комплекс гибридов $\mathrm{F}_{1}$ и $\mathrm{F}_{2}$, полученный в 2008 и 2009 гг. скрещиванием шести сортов - Омский голозёрный 1 (Омская обл.), Condor (Канада), Нутанс 553 (Саратовская обл.), Анна (Оренбургская обл.), Лунь (Пензенская обл.), Margret (Германия). Опыты размещались по чистому пару в двух рендомизированных блоках.
Площадь делянок составляла 0,4 $\mathrm{M}^{2}\left(\mathrm{~F}_{1}\right)$ и $1,0 \mathrm{M}^{2}$ (родители и $\mathrm{F}_{2}$ ), площадь питания одного растения - 5×20 см. Анализ элементов структуры урожая выполняли на 30 растениях с каждого повторения, убранных вручную с корнями.

Генетический анализ в диаллельном комплексе проводили по В. І. Hayman [17], комбинационную способность определяли по I методу В. Griffing [18], коэффрициенты наследуемости - по М. А. Федину с соавторами [19].

Погодные условия лет исследований были контрастными. За период вегетации ячменя в 2009 г. выпало 206 мм осадков, гидротермический коэффрициент (ГТК) составил 1,4 (достаточное увлажнение), а в 2010 г. - 18,7 мм осадков и ГТК 0,13 (острая засуха).

\section{Результаты}

В среднем по опыту высота родительских сортов составила в 2009 г. 80,0 см, в

Высота растений у диаллельных гибридов ячменя

Таблица 1

\begin{tabular}{|c|c|c|c|c|c|c|}
\hline \multirow{3}{*}{$\begin{array}{c}\text { Сорт, } \\
\text { гибридная } \\
\text { популяция }\end{array}$} & \multicolumn{6}{|c|}{ Масса 1000 зёрен, г; тип наследования } \\
\hline & \multicolumn{2}{|c|}{$2009 F_{1}$} & \multicolumn{2}{|c|}{$2010 \mathrm{~F}_{1}$} & \multicolumn{2}{|c|}{$2010 F_{2}$} \\
\hline & Прямые & Обратные & Прямые & Обратные & Прямые & Обратные \\
\hline $\mathrm{O}$ & \multicolumn{2}{|c|}{86,2} & \multicolumn{2}{|c|}{68,4} & \multicolumn{2}{|c|}{68,4} \\
\hline C & \multicolumn{2}{|c|}{75,8} & \multicolumn{2}{|c|}{54,0} & \multicolumn{2}{|c|}{53,8} \\
\hline $\mathrm{M}$ & \multicolumn{2}{|c|}{73,4} & \multicolumn{2}{|c|}{57,8} & \multicolumn{2}{|c|}{57,4} \\
\hline ת & \multirow{2}{*}{\multicolumn{2}{|c|}{$\begin{array}{l}79,7 \\
78,4\end{array}$}} & \multirow{2}{*}{\multicolumn{2}{|c|}{$\begin{array}{l}63,6 \\
57,7\end{array}$}} & \multirow{2}{*}{\multicolumn{2}{|c|}{$\frac{63,3}{58,1}$}} \\
\hline $\mathrm{H}$ & & & & & & \\
\hline$A$ & \multicolumn{2}{|c|}{87,5} & \multicolumn{2}{|c|}{71,4} & \multicolumn{2}{|c|}{71,1} \\
\hline $\mathrm{O} / \mathrm{C}$ & $86,1 \mathrm{~g}^{+}$ & 90,4 сд+ & 62,6 нд+ & 67,8 нд+ & 62,2 нд+ & 67,9 нд+ \\
\hline $\mathrm{O} / \mathrm{M}$ & $85,4 \mathrm{нд}+^{+}$ & $88,1 \mathrm{cg}^{+}$ & 67,9 нд + & 67,8 нд+ & $69,9 \mathrm{cд}^{+}$ & $67,5 \mathrm{Hд}^{+}$ \\
\hline О/Л & 79,5 д- & 84,6 нд+ & $65,5 \mathrm{нд-}$ & 70,6 сд+ & 65,0 нд- & 71,4 сд+ \\
\hline$\overline{\mathrm{O} / \mathrm{H}}$ & 87,7 сд+ & 89,2 сд+ $^{+}$ & 66,3 нд+ & 67,9 нд+ & 65,4 нд+ & 67,3 нд+ \\
\hline $\mathrm{O} / \mathrm{A}$ & 95,1 сд+ & 98,0 сд+ & 75,6 сд+ & 71,7 сд+ & 72,1 сд+ & 71,5 сд+ \\
\hline $\mathrm{C} / \mathrm{M}$ & 78,0 сд+ & 84,9 сд+ & 62,9 сд+ & 70,0 сд+ & 62,4 сд+ & $72,1 \mathrm{cд}+^{+}$ \\
\hline С/Л & 77,2 нд- & 78,2 нд+ & 58,4 нд- & 59,2 нд+ & 57,8 нд- & 60,4 нд+ \\
\hline $\mathrm{C} / \mathrm{H}$ & 78,0 нд+ & 77,5 нд+ & 64,0 сд+ & 63,9 сд+ $^{+}$ & 63,6 сд+ & 64,2 сд+ \\
\hline $\mathrm{C} / \mathrm{A}$ & 88,6 сд+ & 93,4 сд+ & 68,4 нд+ & 66,8 нд+ & 67,8 нд+ & 66,7 нд+ \\
\hline Л/M & 82,0 сд+ & 87,4 сд+ & 61,7 нд+ & 66,3 сд+ & 61,3 нд+ & 65,9 сд+ \\
\hline$\pi / \mathrm{H}$ & 82,8 сд+ & 79,3 нд+ & 67,2 сд+ & 66,5 сд+ & 66,9 сд+ & 66,3 сд+ \\
\hline$\pi / A$ & 87,5 д $^{+}$ & 84,3 нд+ & 72,7 сд $^{+}$ & 70,7 нд+ & 72,5 сд $+^{+}$ & 70,2 нд+ \\
\hline $\mathrm{H} / \mathrm{M}$ & 77,7 д+ $^{+}$ & 87,4 сд+ & 66,9 сд+ & 66,3 сд $^{+}$ & 66,7 сд $+^{+}$ & 65,9 сд+ \\
\hline $\mathrm{H} / \mathrm{A}$ & 86,4 нд+ & 82,90 & 72,7 сд+ & 68,4 нд+ & 72,4 сд+ & 68,0 нд+ \\
\hline $\mathrm{A} / \mathrm{M}$ & 88,9 сд+ & 88,9 сд+ & 69,6 нд+ & 69,6 нд+ & 70,1 нд+ & 70,1 нд+ \\
\hline Среднее по опыту & & & & & & \\
\hline $\mathrm{HCP}_{05}$ & & & & & & \\
\hline Ошибка опыта, \% & & & & & & \\
\hline \multicolumn{7}{|c|}{$\begin{array}{l}\text { Примечания: } \\
\text { 1. Обозначения сортов: А - Анна, Л - Лунь, M - Margret, Н - Нутанс 553, О - Омский голо- } \\
\text { зёрный 1, С - Condor; } \\
\text { 2. Обозначения типов наследования: «0»- промежуточное наследование; «нд+»- неполное } \\
\text { доминирование в сторону родителя с большим значением признака; «нд-» - неполное до- } \\
\text { минирование в сторону родителя с меньшим значением признака; «д+»- доминирование } \\
\text { высокорослости, «д-» - доминирование низкорослости «сд+» - сверхдоминирование; } \\
\text { «сд-»-депрессия. }\end{array}$} \\
\hline
\end{tabular}


2010 г. - 62,0 см. Гибриды, в среднем, были выше на 4,9-5,0 см (табл. 1). Родительские формы достоверно различались по высоте растений в оба года исследований. Наибольшей высотой отличались сорта Омский голозёрный 1 (86,2 см в 2009 г. и 68,5 см в 2010 г.), Анна $(87,5$ и 70,8 cм), наименьшей - Margret $(73,4$ и 56,8 см), Condor (75,8 и 53,7 см) и Нутанс 553 (78,4 и 58,9 см). Острозасушливые условия 2010 г. привели к значительному снижению высоты растения по сравнению с благоприятным 2009 г., особенно у сортов Нутанс 553 и Condor (на 26 и $29 \%$ соответственно).

Наибольшая депрессия высоты растений в засушливый год (23-29 \%) отмечена у прямых и обратных гибридов Омского голозёрного 1 с сортами Condor и Нутанс 553, сорта Condor с сортами Омский голозёрный 1, Лунь и Анна, от скрещиваний между сортами Лунь и Margret, а также у отдельных гибридов: Анна/Омский голозёрный 1 и Margret / Нутанс 553.

Наименьшее снижение высоты растений при засухе отмечено у прямых и обратных комбинаций скрещиваний сортов Омский голозёрный 1 и Лунь, Condor и Hyтанс 553, Лунь и Анна, Нутанс 553 и Анна, а также у отдельных гибридов: Margret/ Condor, Нутанс 553/Лунь, Нутанс 553/ Margret (14-18\%, что ниже, чем у лучшего по данному показателю сорту Анна - $18 \%$ ).

При скрещивании форм, слабо различавшихся по высоте растений (Омский голозёрный 1 и Анна; Condor и Margret; Hyтанс 553 с сортами Condor, Margret и Лунь), в $F_{1}$ и $F_{2}$, как правило, наблюдалось сверхдоминирование. Однако, в 2009 г. у гибридов Condor / Нутанс 553, Нутанс 553 / Condor и Нутанс 553 / Лунь наблюдалось неполное доминирование; у гибрида Нутанс 553 / Margret - полное доминирование.

Полное или частичное доминирование более высокорослого родителя стабильно проявляли прямые и обратные гибриды Омский голозёрный 1/Condor. На характеристики доминирования некоторых комбинаций оказывали влияние условия года: так, гибриды Омский голозёрный 1 / Нутанс 553, Condor / Анна, Анна / Margret и их реципроки в 2009 г. проявили сверхдоминирование, а в 2010 г. - частичное доминированием более высокорослого родителя.

Сравнение гибридов $F_{1}$ и $F_{2}$, выращенных в 2010 г., не показало изменения степени доминирования от поколения к поколению. Исключение составил гибрид Омский голозёрный 1 / Margret, который в $\mathrm{F}_{1}$ проявлял неполное доминирование высокорослости, а в $\mathrm{F}_{2}$ - сверхдоминирование.

Гибриды между сортами Омский голозёрный 1 и Margret, Лунь и Margret, Лунь и Анна, Нутанс 553 и Анна проявляли положительное доминирование (только гибрид Анна / Нутанс 553 в 2009 г. показал промежуточное наследование). На проявление степени доминирования у остальных гибридных комбинаций условия года оказывали большее влияние, показывая в разных случаях промежуточное наследование, уклонение в сторону более высокорослого родителя и сверхдоминирование.

Степень доминирования у ряда гибридов зависела от направления скрещиваний. Так, прямые комбинации Омский голозёрный 1 / Лунь отличались частичным или полным доминированием более низкорослого родителя, тогда как обратные комбинации - частичным доминированием с противоположным знаком и даже сверхдоминированием. Гибриды между сортами Condor и Лунь постоянно характеризовались неполным доминированием, однако у прямых и обратных комбинаций противоположные знаки доминирования. Гибрид Анна / Лунь снижал степень доминирования,

Таблица 2

Комбинационная способность сортов ячменя для признака «высота растений»

\begin{tabular}{|c|c|c|c|c|c|c|c|c|c|}
\hline \multirow[b]{2}{*}{ Сорт } & \multicolumn{3}{|c|}{$\mathrm{F}_{1}$ (2009 год) } & \multicolumn{3}{|c|}{$F_{1}(2010$ год) } & \multicolumn{3}{|c|}{$\mathrm{F}_{2}$ (2010 год) } \\
\hline & $\begin{array}{c}\text { Эффрект } \\
\text { ОКС } g_{i}\end{array}$ & $\begin{array}{l}\text { Вари- } \\
\text { анса } \\
\text { ОКС } \sigma_{\text {gi }}^{2}\end{array}$ & $\begin{array}{c}\text { Вари- } \\
\text { анса } \\
\text { СКС } \sigma^{2}{ }_{s i}\end{array}$ & \begin{tabular}{|c} 
Эфрфрект \\
ОКС $\mathrm{g}_{\mathrm{i}}$
\end{tabular} & $\begin{array}{l}\text { Вари- } \\
\text { анса } \\
\text { ОКС } \sigma^{2}\end{array}$ & $\begin{array}{c}\text { Вари- } \\
\text { aнса } \\
\text { CKC } \sigma^{2}{ }_{\text {si }}\end{array}$ & $\begin{array}{c}\text { Эффрект } \\
\text { ОКС } g_{i}\end{array}$ & $\begin{array}{c}\text { Вари- } \\
\text { aнса } \\
\text { OKC } \sigma_{g i}^{2}\end{array}$ & $\begin{array}{c}\text { Вари- } \\
\text { aнса } \\
\text { CKC } \sigma^{2} \text { si }\end{array}$ \\
\hline Ом. гол. 1 & $3,97 b c$ & 15,51 & 8,32 & $2,10 c$ & 4,22 & 0,83 & $1,86 c$ & 3,29 & 0,70 \\
\hline Condor & $-2,10 a$ & 4,15 & 5,95 & $-3,15 a$ & 9,73 & 7,86 & $-3,51 a$ & 12,16 & 7,81 \\
\hline Margret & $-1,93 a$ & 3,47 & 6,18 & $-0,61 b$ & 0,17 & 8,71 & $-0,60 b$ & 0,20 & 6,63 \\
\hline Лунь & $-2,22 a$ & 4,68 & 9,14 & $-1,51 a b$ & 2,07 & 2,34 & $-0,88 b$ & 0,61 & 3,70 \\
\hline Нутанс 553 & $-2,73 a$ & 7,21 & 4,33 & $-1,03 b$ & 0,87 & 1,97 & $-0,94 b$ & 0,73 & 2,88 \\
\hline Анна & $5,01 \mathrm{c}$ & 24,87 & 6,99 & $4,20 \mathrm{~d}$ & 17,46 & 1,57 & $4,07 d$ & 16,43 & 0,97 \\
\hline Среднее & & 9,98 & 6,82 & & 5,75 & 3,88 & & 5,57 & 3,78 \\
\hline $\mathrm{HCP}_{05}$ & 1,83 & & & 1,64 & & & 1,46 & & \\
\hline $\begin{array}{l}r \text { между ОКС } \\
\text { и признаком }\end{array}$ & & 0,90 & & & 0,91 & & & 93 & \\
\hline
\end{tabular}


по сравнению с комбинацией Лунь / Анна: от полного доминирования высокорослости в 2009 г. и сверхдоминирования в 2010 г. до частичного доминирования; похожая картина наблюдается у гибридов от скрещивания сортов Нутанс 553 и Анна.

Гибриды между сортами Омский голозёрный 1 и Лунь также меняли доминирование: от доминирования низкорослого родителя в прямой комбинации до доминирования высокорослого в обратной комбинации в 2009 году, и, соответственно, от промежуточного наследования до сверхдоминирования в 2010 году. Менее стабильные сдвиги степени доминирования наблюдались в реципрокных гибридах между сортами Омский голозёрный и Нутанс 553, Анна и Condor, Лунь и Margret.

Анализ комбинационной способности сортов показал достоверный вклад в дисперсию признака эффектов общей комбинационной способности (ОКС) и специфической комбинационной способности (СКС) и реципрокного эффректа (табл. 2).

Сравнивая вариансы ОКС и СКС в целом, можно отметить преобладание аддитивных эфффектов в 2009 и 2010 гг. Однако, сорта различаются по проявлению аддитивных и неаддитивных эффеектов.

У сортов Омский голозёрный 1 и Анна варианса ОКС превышает вариансу СКС, свидетельствуя о преимущественном вкладе аддитивных эффектов. Эти сорта будут повышать высоту растений в потомстве, о чём говорят и их эффректы ОКС. Другие сорта могут быть использованы в селекции для снижения высоты растений на основании значения ОКС, однако успех отбора будет затруднён из-за неаддитивного влияния (сравнение варианс в пользу СКС).

Условия года влияли на генетические системы, определяющие высоту растений некоторых сортов. Так, у сорта Condor в
2010 г. усиливается вклад аддитивных эффектов, а у сорта Лунь, напротив, усиливаются неаддитивные влияния.

Коэффициент корреляции между ОКС и выраженностью признака у родительских сортов стабильно высокий и положительный. Можно сделать вывод, что подбор пар на увеличение и уменьшение высоты растений можно проводить на основании выраженности признака у родительских сортов.

Анализ по Хейману показывает, что в 2009 г. в $F_{1}$ высота растений контролировалась аддитивно-доминантной генетической системой с преобладанием эфффектов сверхдоминирования (линия регрессии пересекает отрицательную полуось $\mathrm{Wr}$, показатель доминирования П6 > 1). Эпистаз несущественен: наклон линии регрессии достоверно не отличается от единичного (табл. 3).

Доминантные и рецессивные аллели, определяющие признак, распределены асимметрично в каждом локусе $\left(\mathrm{H}_{2} / 4 \mathrm{H}_{1}=\right.$ $0,21)$ и у родительских сортов в целом (П13 < 1); в наборе сортов преобладают рецессивные гены $(\mathrm{F}<0, \Pi 13<1)$.

Коэффрициент корреляции между средними значениями родительских фрорм и уровнем доминирования (суммой $\mathrm{W}_{\mathrm{r}}+\mathrm{V}_{\mathrm{r}}$ ) высокий и отрицательный. То есть признак увеличивают, в основном, доминантные гены.

Сорта на графрике располагаются следующим образом: наибольшей суммой доминантных генов характеризуется сорт Лунь, хотя и его генотип не объединяет все имеющиеся доминантные аллели; сорта Анна, Омский голозёрный 1 и Нутанс 553 содержат примерно 50-75 \% доминантных аллелей, Condor и Margret - около $75 \%$ рецессивных аллелей (рисунок).

В 2010 г. соответствие аддитивно-доминантной модели доказано только для

Таблица 3

Анализ генетических параметров для признака «высота растений»

\begin{tabular}{|c|c|c|c|}
\hline Генетические параметры & $F_{1}(2009$ год) & $\mathrm{F}_{1}(2010$ год) & $\mathrm{F}_{2}(2010$ год) \\
\hline $\mathrm{D}$ & $30,10^{*}$ & $42,88^{*}$ & $44,46^{*}$ \\
\hline $\mathrm{F}$ & $-8,47$ & 22,87 & 23,57 \\
\hline $\mathrm{H}_{1}$ & $53,14^{*}$ & $42,86^{*}$ & $38,41^{*}$ \\
\hline $\mathrm{H}_{2}$ & $43,68^{*}$ & 35,10 & $32,40^{*}$ \\
\hline $\mathrm{E}$ & $3,83^{*}$ & 3,95 & 2,54 \\
\hline$(\Pi 6) \sqrt{ } \mathrm{H}_{1} / \mathrm{D}$ & 1,33 & 0,9998 & 0,93 \\
\hline$(\Pi 9) \mathrm{H}_{2} / 4 \mathrm{H}_{1}$ & 0,21 & 0,20 & 0,21 \\
\hline (П13) $\sqrt{4} \mathrm{DH}_{1}+\mathrm{F} / \sqrt{4 \mathrm{DH}_{1}-\mathrm{F}}$ & 0,81 & 1,73 & 1,80 \\
\hline Наследуемость в широком смысле $\left(\mathrm{H}^{2}\right)$ & 0,90 & 0,85 & 0,89 \\
\hline Наследуемость в узком смысле $\left(\mathrm{h}^{2}\right)$ & 0,62 & 0,52 & 0,56 \\
\hline$r$ между $X_{p}$ и $W_{r}+V_{r}$ & $-0,71$ & $-0,87^{*}$ & $-0,88^{*}$ \\
\hline $\mathrm{b}_{\mathrm{Wr} / \mathrm{rr}}$ & 0,82 & $0,40^{*}$ & $0,43^{*}$ \\
\hline
\end{tabular}

*критерий достоверен на уровне значимости $\mathrm{P}=0,05$. 


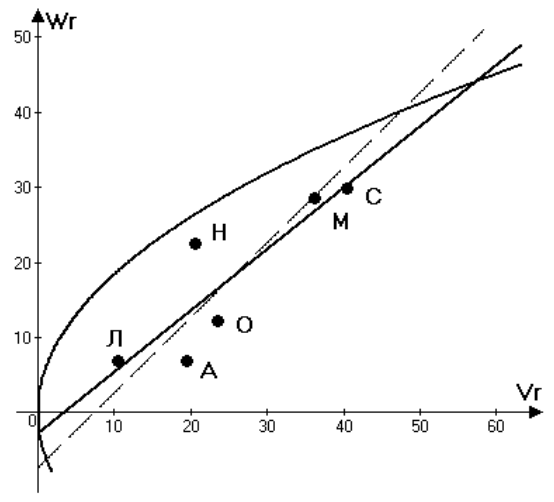

$F_{1}, 2009$ 2.

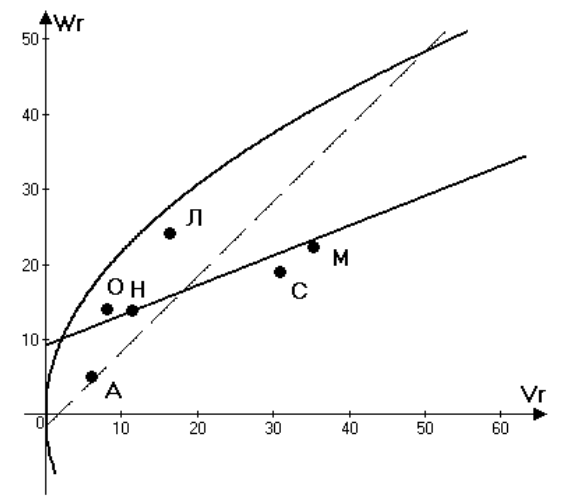

$F_{1}, 2010$ 2.

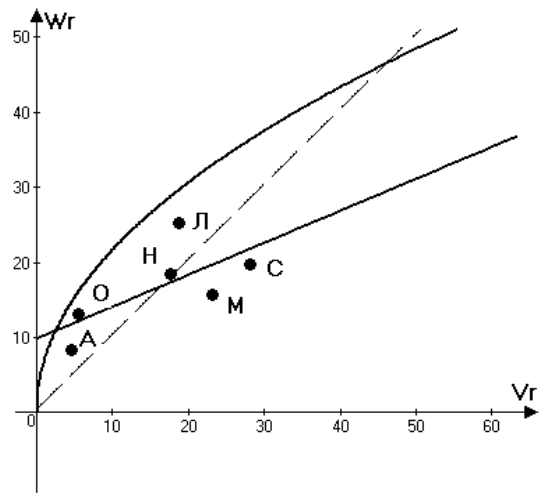

$F_{2}, 20102$

Графрики Хеймана Wr/Vr для признака «высота растений»

поколения $\mathrm{F}_{1}$. В обоих поколениях проявляется неполное доминирование (линия регрессии пересекает положительную полуось $\mathrm{Wr}, \Pi 6<1)$ и сильные эпистатические эффректы (линия регрессии существенно отклоняется от 1).

Параметр П9 $\neq 0,25$ указывает на асимметрию распределения плюс и минус аллелей в локусах. Параметр П13 > 1 говорит о преобладании доминантных генов у родительских сортов и подтверждает асимметрию. Асимметрия вместе с эпистазом вносят шумы в анализ по Хейману, поэтому ограничимся анализом графической информации и параметров, не вызывающих сомнения.

В 2010 г. признак также увеличивали доминантные гены ( $\mathrm{r}_{\mathrm{x} /(\mathrm{Wr}+\mathrm{Vr})}$ отрицателен, высок и достоверен). Все сорта находятся ближе к доминантной зоне графиков Хеймана. Самый высокий уровень доминантных аллелей - у сортов Анна и Омский голозёрный 1, которые расположены близко к точке пересечения линии регрессии и параболы. Это подтверждается генетическими параметрами Fr, которые достоверны в $F_{2}$ для обоих сортов и для сорта Анна в обоих поколениях.

Значения коэффициентов наследуемости подтверждают наличие аддитивных эффректов в контроле признака: коэффициент наследуемости в узком смысле варьи- ровал от 0,52 до 0,62, в широком смысле от 0,85 до 0,90. Всё это говорит, скорее, о средней степени наследуемости признака.

\section{Заключение}

Таким образом, в контроле высоты растения преобладали аддитивные эффекты (наследование по типу полного и неполного доминирования, увеличивают высоту доминантные гены). Признак должен быть отзывчив на отбор, что подтверждают и коэффициенты наследуемости: в широком смысле 0,85-0,90; в узком смысле 0,52-0,62. Наличие комплементарного эпистаза увеличивает вероятность получения отрицательных трансгрессий, повышая успех селекции на снижение высоты.

В изучаемой системе сортов существует резерв снижения высоты, поскольку ни один из них не обладает всеми рецессивными аллелями, уменьшающими признак. У сортов Анна и Омский голозёрный 1 стабильно преобладают доминантные аллели, которые они будут передавать потомству, увеличивая высоту. Данные сорта следует использовать в комбинациях с более низкорослыми родителями. Condor и Margret имеют более высокое число рецессивных аллелей и могут рассматриваться как доноры снижения высоты. Нутанс 553 и Лунь меняют своё расположение на графике в зависимости от года и поколения.

\section{Лumepamypa}

1. Перспективные образцы ярового ячменя для селекции в Нечерноземной зоне РСФСР / К. С. Горелик, И. А. Терентьева, Н. Д. Никитина [и др.] // Генетика и селекция ржи и зернофуражных культур: сборник трудов по прикладной ботанике, генетике и селекции. - Ленинград, 1985. T. 95. - С. 38-45.

2. Зенищева, Л. С. Селекция ярового ячменя в Чехословакии / Л. С. Зенищева // Селекция и семеноводство. - 1991. - № 1. - С. 60-61.

3. Гриб, С. И. Из опыта селекции ярового ячменя в ГДР / С. И. Гриб, К. Г. Шашко // Селекция и семеноводство. - 1980. - № 1. - С. 44-45.

4. Коданев, И. М. Ячмень / И. М. Коданев - Москва, 1964. - 233 с.

5. Бахтеев, Ф. Х. Сорта ячменя Советского Союза / Ф. Х. Бахтеев, В. М. Леонтьев // Селекция и семеноводство. - 1938. - № 1. - С. 22-24. 
6. Ильин, А. В. Селекция ярового ячменя на продуктивность в сухостепных условиях Саратовского Заволжья / А. В. Ильин // Эволюция научных технологий в растениеводстве. Т. 2: Тритикале. Сортоизучение и семеноводство. Ячмень. - Краснодар, 2004. - С. 177-181.

7. Горшкова, В. А. Яровой ячмень / В. А. Горшкова, В. Т. Рымарь. - Каменная степь, 1998. $312 \mathrm{c}$.

8. Verma, A. K. Genetic architecture for yield and quality component traits over two environments in barley (Hordeum vulgare L.) / A. K. Verma, S. R. Vishwakarma, P. K. Singh // Barley Genetics Newsletter. $-2007 .-$ V. 37. - P. 24-28.

9. Inheritance of stem height and second-internode length in barley hybrids / M. Madic, D. Kneževic, A. Paunovic [at al.]. - Genetika. - 2009. - V. 41. - № 3. - P. 229-236.

10. Jeżowski, S. Genetic control of morphological and physical characteristics determining resistance to lodging in barley (Hordeum vulgare L.) / S. Jeżowski, M. Surma, T. Adamski // Int. Agrophysics. - 2001. - V. 15. - P. 157-160.

11. Genetic analysis of morphological and physical stem characteristics determining lodging resistance in two- and six-rowed barley (Hordeum vulgare L.) lines / S. Jeżowski, M. Surma, T. Adamski [et al.] // Int. Agrophysics. - 2005. - V. 19. - P. 299-303.

12. Variation of some physical and geometrical stem features in doubled haploids of barley / S. Jeżowski, T. Adamski, M. Surma [et al.] // Int. Agrophysics. - 2000. - V. 14. - P. 187-189.

13. Eshghi, R. Inheritance of some important agronomic traits in hulless barley / R. Eshghi, E. Akhundova // International Journal of Agriculture \& Biology. - 2010. - V. 12. - № 1. - P. 73-76.

14. Sears, R. G. Inheritance of Dwarf and Semidwarf Plant Height in Barley / R. G. Sears, W. E. Kronstad, R. J. Metzger // Crop Science. - 1981. - V. 21. - № 6. - P. 828-833.

15. Vimal, S. C. Gene effects controlling yield components in barley (Hordeum vulgare L.) / S. C. Vimal, S. R. Vishwakarma // Rachis. - 1999. - V. 18. - № 2. - P. 21-25.

16. Королева, Л. И. Использование данных диаллельного анализа для оценки источников хозяйственно полезных признаков ячменя / Л.И.Королева // Растительные ресурсы в селекции важнейших сельскохозяйственных культур нечерноземной зоны РСФСР: сборник научных трудов по прикладной ботанике, генетике и селекции - Ленинград, 1988. - Т. 122. - С. 104-109.

17. Hayman, B. I. The theory and analysis of diallel crosses / B. I. Hayman // Genetics. - 1954. - V. 10. - P. 235-244.

18. Griffing, B. Concept of general and specific combining ability in relation to diallel crossing systems / B. Griffing // Australian Journal of Biological Sciences. - 1956. - V. 9. - P. 463-493.

19. Федин, М. А. Статистические методы генетического анализа / М. А. Федин, Д. Я. Силис, А. В. Смиряев. - Москва: Колос, 1980. - 207 с.

UDC 633.16:631.523.2

DOI 10.36461/NP.2020.54.1.009

\section{HERITAGE AND GENETIC CONTROL OF BARLEY PLANT HEIGHT}

\section{O. Dolzhenko, Candidate of Agricultural Sciences}

Penza University of Agriculture - branch of the Federal State-Funded Scientific Institution Federal Scientific Center of Fibre Crops, w. s. Lunino, Penza oblast, Russia, t. +7 (84161) 3-18-07, e-mail: d.dolzhenko.pnz@fnclk.ru

The inheritance of the height of barley plants was studied in the system of diallel crossing $(6 \times 6)$ in the conditions of the forest-steppe of the Middle Volga in contrasting hydrothermal conditions. An analysis of combinational ability according to B. Griffing and genetic analysis according to B. Hayman showed the predominance of additive effects in the control of the trait (inheritance by type of complete and incomplete dominance). The trait should be responsive to selection, which is confirmed by the heritability coefficients: in the broad sense $\left(\mathrm{H}^{2}\right), 0.85-0.90$; in the narrow sense $\left(\mathrm{h}^{2}\right)-0.52-0.62$. Dominant genes increased the height of plants. The presence of complementary epistasis increases the likelihood of negative transgressions, increasing the success of breeding to reduce plant height. None of the varieties of the diallel complex possessed all recessive alleles that reduced the trait. Varieties Anna and Omsky Golozyorny 1, with dominant alleles, will increase the height of plants in the offspring. These varieties should be used in combination with shorter parents. Varieties Condor and Margret have a higher number of recessive alleles and can be considered as donors of height reduction. Promising for selection hybrid populations have been identified.

Keywords: barley, diallel analysis, plant height, genetic systems, combinational ability, heritability coefficient. 


\section{Reference:}

1. Gorelik, K. S., Terentyev I. A., Nikitina N. D. [et al.]. Promising samples of spring barley for selection in the Non-Chernozem zone of the RSFSR. Genetics and selection of rye and grain crops: a collection of works on applied botany, genetics and selection, vol. 95. Leningrad, 1985, p. 38-45.

2. Zenishcheva, L. S. Selection of spring barley in Czechoslovakia. Breeding and seed production, 1991, No. 1, p. 60-61.

3. Grib, S. I., Shashko K. G. From the experiment of selection of spring barley in the GDR. Breeding and seed production, 1980, No. 1, p. 44-45.

4. Kodanev, I. M. Barley. Moscow, 1964, 233 p.

5. Bakhteev, F. Kh., Leontiev V. M. Variety of barley of the Soviet Union. Breeding and seed production, 1938, No. 1, p. 22-24.

6. Ilyin, A. V. Selection of spring barley for productivity in dry steppe conditions of the Saratov TransVolga region. The evolution of scientific technology in crop production. T. 2: Triticale. Variety study and seed production. Barley. Krasnodar, 2004, p. 177-181.

7. Gorshkova, V. A., Rymar V. T. Spring barley. Stone Steppe, 1998, 312 p.

8. Verma, A. K., Vishwakarma S. R., Singh P. K. Genetic architecture for yield and quality component traits over two environments in barley (Hordeum vulgare L.). Barley Genetics Newsletter, 2007, v. 37, p. 24-28.

9. Madic, M., Kneževic D., Paunovic A. [at al.]. Inheritance of stem height and second-internode length in barley hybrids. Genetika, 2009, v. 41, № 3, p. 229-236.

10. Jeżowski, S., Surma M., Adamski T. Genetic control of morphological and physical characteristics determining resistance to lodging in barley (Hordeum vulgare L.). Int. Agrophysics, 2001, v. 15, p. 157-160.

11. Jeżowski, S., Surma M., Adamski T. [et al.] Genetic analysis of morphological and physical stem characteristics determining lodging resistance in two- and six-rowed barley (Hordeum vulgare L.) lines. Int. Agrophysics, 2005, v. 19, p. 299-303.

12. Jeżowski, S., Adamski T., Surma M. [et al.] Variation of some physical and geometrical stem features in doubled haploids of barley. Int. Agrophysics, 2000, v. 14, p. 187-189.

13. Eshghi, R., Akhundova E. Inheritance of some important agronomic traits in hulless barley. International Journal of Agriculture \& Biology, 2010, v. 12, № 1, p. 73-76.

14. Sears, R. G., Kronstad W. E., Metzger R. J. Inheritance of Dwarf and Semidwarf Plant Height in Barley. Crop Science, 1981, v. 21, № 6, p. 828-833.

15. Vimal, S. C., Vishwakarma S. R. Gene effects controlling yield components in barley (Hordeum vulgare L.). Rachis, 1999, v. 18, № 2, p. 21-25.

16. Koroleva, L. I. Using the data of diallel analysis to assess the sources of economically useful signs of barley. Plant resources in the selection of the most important crops of the non-chernozem zone of the RSFSR: a collection of scientific papers on applied botany, genetics and selection. Leningrad, 1988, v. 122, p. 104-109.

17. Hayman, B. I. The theory and analysis of diallel crosses. Genetics, 1954, v. 10, p. 235-244.

18. Griffing, B. Concept of general and specific combining ability in relation to diallel crossing systems. Australian Journal of Biological Sciences, 1956, v. 9, p. 463-493.

19. Fedin, M. A., Silis D. Ya., Smiryaev A. V. Statistical methods of genetic analysis. Moscow: Kolos, 1980, 207 p. 